\title{
Proportional mortality patterns among chemical plant workers exposed to formaldehyde
}

\author{
G M MARSH \\ From the Department of Biostatistics, Graduate School of Public Health, University of Pittsburgh, Pittsburgh, \\ PA 15261, USA
}

\begin{abstract}
To examine the possible health risks associated with occupational exposure to formaldehyde a proportional mortality analysis was conducted on deaths occurring between 1950 and 1976 among 136 men who had been employed a month or more in one of five formaldehyderelated areas of a large chemical producing plant located in Springfield, Massachusetts, USA. Overall, no statistically significant excesses or deficits in proportional mortality were observed among the formaldehyde-exposed group based on comparisons with both United States men and men from the local county area. In addition, no important differences in mortality were observed among this group when comparisons were made with 456 male decedents from the same plant who had not had a month or more of formaldehyde exposure. Within the calendar period examined, no deaths from sinonasal cancer were observed among the chemical workers studied nor was mention made on any death certificate of sinonasal cancer as a contributory cause of death. No important excesses, trends, or patterns in cancer mortality were observed among white male formaldehyde-exposed workers when consideration was given to age and time period of death, type and duration of formaldehyde exposure, and the lapsed period from the onset of the first formaldehyde-related job assignment. Although certain limitations of this study do not allow definite conclusions to be drawn, the results indicate no trends or patterns in proportional mortality that could be directly linked to exposures to formaldehyde.
\end{abstract}

Formaldehyde $\left(\mathrm{CH}_{2} \mathrm{O}\right)$ is a colourless, flammable gas with a strong, pungent odour. As an important industrial chemical of major commercial use, formaldehyde is found throughout the environment. In outdoor air it can originate from many sources, such as incinerators, photochemical smog, and engine exhaust. Atmospheric concentrations of formaldehyde have been reported to range from under $0.005 \mathrm{ppm}$ to $0.6 \mathrm{ppm}$ near industrial outlets or in areas of heavy smog. ${ }^{1}$ Cigarette smoke contains as much as $40 \mathrm{ppm}$ of formaldehyde by volume.

The United States produced about 6.4 billion pounds of aqueous formaldehyde in 1978, and the consumption there by the year 1983 will probably exceed 7.5 billion pounds. ${ }^{2}$ Half of the formaldehyde produced is used to produce synthetic resins such as urea-formaldehyde and phenolformaldehyde resins. A partial list of products made with or containing formaldehyde include: adhesives,

Received 12 March 1982

Accepted 18 May 1982 cosmetics, dyes, embalming fluids, fertilisers, fibreboard, insulation foam, paints, paper, pharmaceuticals, plastic, rubber, and textiles.

The United States National Institute for Occupational Safety and Health (NIOSH) had estimated that 800 employees may be at risk of exposure to the high concentrations of formaldehyde found in industrial synthesis, formulation, and distribution of concentrated products. ${ }^{3}$ The numerous uses of formaldehyde and its derivatives indicate, however, that a substantially larger population of employees may be at risk from intermittent exposures to products containing sources of formaldehyde or its congeners and derivatives.

Occupational exposures usually result from the release of free formaldehyde vapour into the air. Principal hazards associated with human exposures to airborne formaldehyde are irritation of the respiratory tract, eye, and skin. ${ }^{4}$ In a recent intelligence bulletin NIOSH recommended that formaldehyde be handled as a potential occupational carcinogen and that appropriate controls be used to 
reduce worker exposure. ${ }^{1}$ These recommendations were based primarily on a Chemical Industry Institute of Toxicology (CIIT) study in which laboratory rats and mice exposed to formaldehyde vapour developed nasal cancer ${ }^{56}$ (WD Kerns, at 3rd CIIT Conference on Toxicology, Raleigh, N Carolina, November 1980). These results were supported by a New York University study, where rats exposed to a mixture of formaldehyde and hydrochloric acid vapours developed nasal cancers. ${ }^{1}$ Formaldehyde has also been shown to be a mutagen in several shortterm laboratory studies. ${ }^{7}$ Currently, there is little information available on the chronic toxicity and potential carcinogenicity related to human exposure to formaldehyde.

This is a report of a proportional mortality study of workers exposed to formaldehyde at a large chemical producing plant in the United States owned and operated by the Monsanto Company. The Monsanto Company started using formaldehyde at its Springfield/Indian Orchard, Massachusetts, plant in 1938. The chemical was used as a raw material in the manufacture of such products as phenolic resins, urea-formaldehyde resins, melamine-formaldehyde resins, hexamethylenetetramine, and resorcinol. Formaldehyde was first produced on a commercial scale at Springfield in 1948. Table 1, which summarises the history of the use and manufacture of formaldehyde at Springfield, shows that several of the original formaldehyde-related processes were discontinued in the 1940s and 1950s. Clearly, some workers were exposed, although no reliable quantitative information is available as to actual exposure levels. Exposure levels to formaldehyde vapour were probably higher, however, in the areas where formaldehyde was present in a liquid form (cast phenolics, resins, other Resinox, Resimines, and formalin plant) compared with levels in areas where formaldehyde had already reacted with other chemicals to form solid or powdered materials (resins compounding and moulding powder) ( $\mathrm{J}$ Henshaw, Monsanto Industrial Hygienist, personal communication, 1980). In addition, owing to major process changes, exposure levels in the late $1930 \mathrm{~s}, 1940 \mathrm{~s}$, and $1950 \mathrm{~s}$ are thought to have been substantially higher than in more recent years. Exposures to formaldehyde that occurred in the service department-waste disposal are relatively insignificant compared with other areas, since they were most likely intermittent and very brief.

It should be recognised that workers were not exposed to formaldehyde alone, but rather to a mixture of chemical substances of variable nature and at various times. This is a major problem for epidemiological studies in much of the chemical industry. Exposure to chemicals used in the production of formaldehyde, for example, may have been as severe as exposure to formaldehyde itself. Moreover, many of the workers were also exposed to other chemicals before or after their formaldehyde-related job assignment. There seems to be no way of separating exposures, and this study was carried out with the full realisation of these possibly confounding factors.

\section{Development of data set}

Three previous unpublished epidemiological studies have examined general mortality patterns among Springfield employees and ex-employees (Stanislawczyk K, Kaminski R, Spirtas R, $A$ proportional mortality analysis of a chemical plant in Massachusetts. Unpublished NIOSH report, May 1978; Proportional mortality study of Monsanto-Indian Orchard plant employees. Unpublished Monsanto report, 1978; and Marsh GM, Final report on the Monsanto Company Indian Orchard plant mortality study. Unpublished University of Pittsburgh, Department of Biostatistics Technical Report, December, 1979). All three studies showed slightly raised mortality risks for cancer of the digestive system and genitourinary tract, although definite conclusions could not be drawn owing to the lack of information on work history and occupational exposures. The most recent unpublished study, mentioned above, conducted by the University of Pittsburgh, Department of Biostatistics, examined mortality during 1950-76 among a cohort of 2490 male wage earners who were employed a minimum

Table 1 Areas of the Monsanto Company, Indian Orchard plant, associated with exposure to formaldehyde

\begin{tabular}{llll}
\hline & Area & Time frame & Material used \\
\hline I & Cast phenolics & $1938-45$ & Formaldehyde, phenol, Na solvents, lactic acid, lead moulds, other \\
II & $\begin{array}{l}\text { Resinox } \\
\text { Resins }\end{array}$ & Formaldehyde, phenol, methanol, xylene, hexamethylenetetramine, \\
& $\begin{array}{l}\text { Resins compounding } \\
\text { Moulding powder }\end{array}$ & $1939-$ present & lump resins (formaldehyde), accelerators, dry powders, other \\
& $\begin{array}{l}\text { Other and unspecified } \\
\text { III } \text { Resimines }\end{array}$ & $1939-58$ & \\
IV Formalin plant & $1939-$ present & \\
V Service department-waste disposal & $1946-$ present & Melamine, butanol, formaldehyde, urea, resorcinol, other \\
\end{tabular}




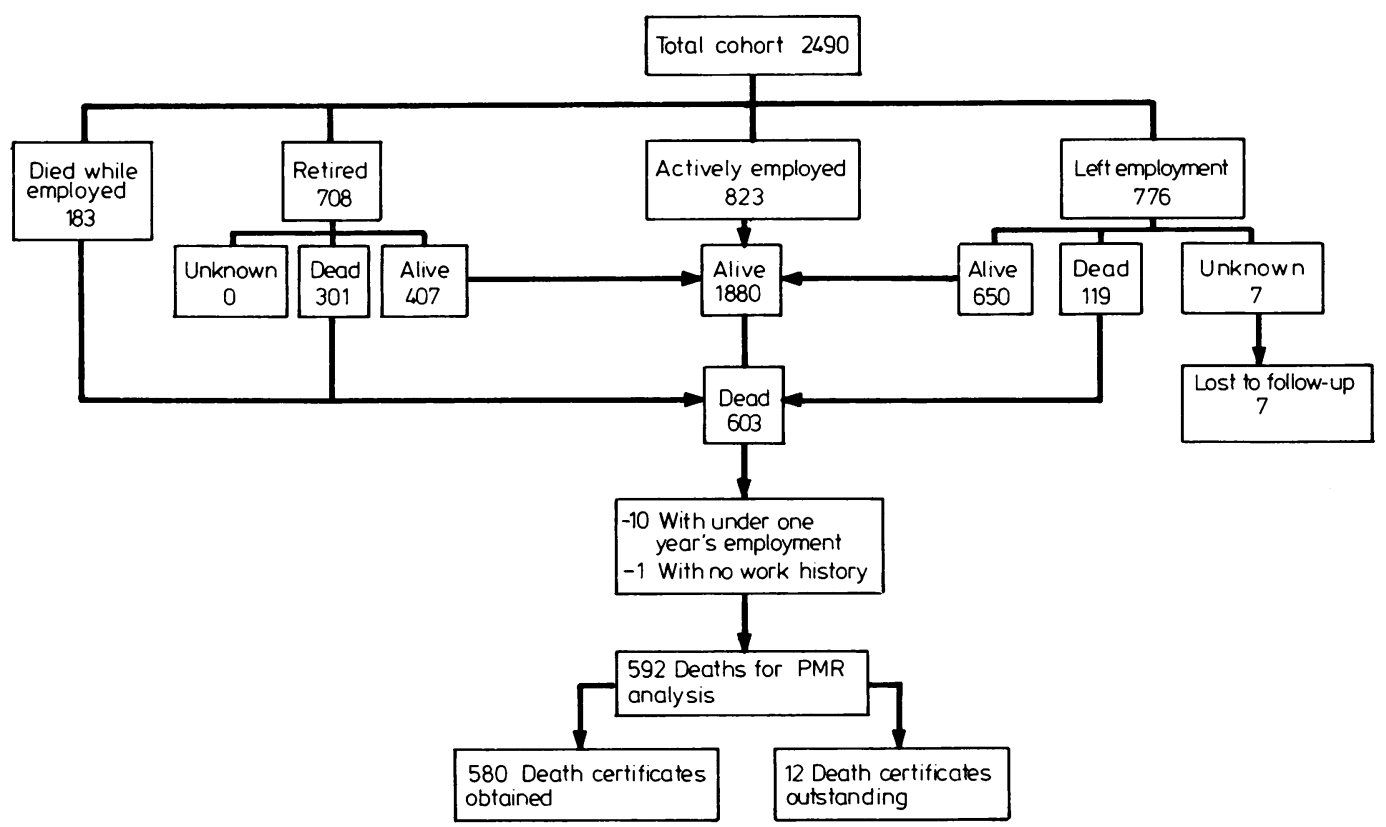

Distribution of total Springfield Plant study population by employment status and vital status, 31 December 1976.

of one year between 1 January 1949 and 31 December 1966.

The distribution of the Springfield study population by working status and vital status as of 31 December 1976 is shown in the figure. The 603 deaths observed during 1950-76 among this cohort served as the basis for the present proportional mortality study. Included in this decedent group were deaths among 301 retirees, 183 active employees, and 119 who terminated employment for reasons other than retirement. All deaths had been independently coded according to the seventh revision of the International Classification of Diseases and Causes of Death. ${ }^{8}$

With the help of Monsanto Company corporate and plant personnel, complete work history data were obtained and processed for all but one decedent. This decedent plus ten others who were found on close inspection of work histories to have had less than one cumulative year of employment were excluded from further study. Detailed analysis of the work history data for the remaining 592 decedents showed that $136(23 \%)$ had one month or more cumulative employment in at least one of the five formaldehyde-related plant areas shown in table 1 , and, as such, comprise the "formaldehyde-exposed" group of interest in this study. Death certificates were obtained for $132(97 \cdot 1 \%)$ of the deaths in the formaldehyde-exposed group and for $448(98.2 \%)$ of the remaining deaths.

Table 2 shows that $15.4 \%$ of the formaldehydeexposed workers are non-white compared with only $2.6 \%$ among the non-exposed workers. To facilitate the statistical analyses, the six decedents with unknown race were assumed to be white.

\section{Methods}

\section{GENERAL MORTALITY}

The relative frequency of specific causes of deaths in the decedent groups of interest was compared with "expected numbers" based on the mortality experience of the white and non-white male populations of the total United States. Using the occupational cohort mortality analysis program (OCMAP), expected numbers of deaths were calculated by applying the cause-specific proportional mortality of United States white and non-white men with the total number of white and non-white deaths in the study group, while indirectly adjusting for age and time period using the 15 age intervals, $<20,20-24$, $25-29, \ldots, 75-79,80-84,85$ or more, and six time periods,. $1950-4,1955-9,1960-4,1965-9$, 1970-4, 1975 and later.'

To adjust for geographical variations in mortality expected numbers of deaths were also computed 
Table 2 Distribution of deaths among male chemical workers by race and work experience

\begin{tabular}{|c|c|c|c|c|c|c|}
\hline \multirow[t]{2}{*}{ Race } & \multicolumn{2}{|c|}{$>1$ month formaldehyde } & \multicolumn{2}{|c|}{ All others } & \multicolumn{2}{|c|}{ Total } \\
\hline & No & $\%$ & No & $\%$ & No & $\%$ \\
\hline $\begin{array}{l}\text { White } \\
\text { Non-white } \\
\text { Unknown } \\
\text { Total }\end{array}$ & $\begin{array}{r}114 \\
21 \\
1 \\
136\end{array}$ & $\begin{array}{r}83.8 \\
15.4 \\
0.8 \\
100.0\end{array}$ & $\begin{array}{r}439 \\
12 \\
5 \\
456\end{array}$ & $\begin{array}{r}96.3 \\
2.6 \\
1.1 \\
100.0\end{array}$ & $\begin{array}{r}553 \\
33 \\
6 \\
592\end{array}$ & $\begin{array}{r}93.4 \\
5.6 \\
1.0 \\
100 \cdot 0\end{array}$ \\
\hline
\end{tabular}

based on the mortality experience of the county population that surrounds the Springfield area and from which the work-force was largely drawn (Hampden County). It was necessary to restrict the observation period to $1960-76$ to make this comparison, since proportional mortalities for nonmalignant causes of death were not available for 1950-9. Proportional mortality ratios (PMRs) were then calculated by taking the ratio of the sum of the observed number of deaths to the sum of the expected number of deaths $(\times 100)$, summation being taken over age group and time period. The major assumption underlying a proportional mortality analysis is that the study and comparison populations have the same mortality rate for all causes of death. Cause-specific PMRs are presented for subgroups of the total decedent group defined by race, age at death, and year of death. Proportional cancer mortality ratios (PCMRs) were also computed for selected cancer sites using age, time, and site-specific proportional cancer mortality to computed expected numbers of deaths. This method assumes that the mortality rate for all cancers was equal in the study and in the comparison populations and compares the relative frequencies of cancers of specific sites. PMRs and PCMRs become unstable with small numbers, and were not computed when based on only one observed death.

The statistical significance of the difference between observed and expected numbers was assessed by a chi-square test with one degree of freedom. ${ }^{10}$ All tests of statistical significance were conducted realising that the probability of a comparison showing significance by chance alone increases with the number of comparisons made. With $\mathbf{n}$ independent comparisons, the probability of falsely claiming statistical significance at the $5 \%$ level in one or more comparisons is $1-(0 \cdot 95)^{n}$.

\section{MORTALITY IN RELATION TO FORMALDEHYDE EXPOSURE}

To examine mortality patterns associated with employment in a particular formaldehyde-related plant area, it was necessary to devise a classification scheme that would assign each decedent to the one plant area that best represented his overall experience of exposure to formaldehyde. The achieve this goal, three different classification schemes were investigated. Scheme 1 categorised the workers into the plant area where first employed, whereas under scheme 2 workers were assigned to the plant area associated with the longest duration of employment. Categorisation under scheme 3 was made if a worker was employed in one and only one formaldehyde-related area throughout his entire work history. This third scheme was an attempt to develop "pure" exposure groups-that is, areaspecific exposure histories uncontaminated by possibly different formaldehyde exposures in other plant areas.

Table 3 shows the distribution of deaths among the formaldehyde-exposed workers by plant area according to these three classification schemes. Interestingly, all three schemes produced very simi-

Table 3 Distribution of deaths among white male formaldehyde-exposed chemical workers by plant area according to three classification schemes

\begin{tabular}{|c|c|c|c|c|c|c|}
\hline \multirow[t]{2}{*}{ Plant area } & \multicolumn{2}{|c|}{ First job } & \multicolumn{2}{|c|}{ Longest duration } & \multicolumn{2}{|c|}{ Pure exposure } \\
\hline & No & $\%$ & No & $\%$ & No & $\%$ \\
\hline $\begin{array}{l}\text { Cast phenolics } \\
\text { Resinox } \\
\text { Resins } \\
\text { Resins compounding } \\
\text { Moulding powder } \\
\text { Unspecified and other } \\
\text { Resimines } \\
\text { Formalin } \\
\text { Service department-waste disposal } \\
\text { Total }\end{array}$ & $\begin{array}{r}2 \\
101 \\
3 \\
0 \\
93 \\
5 \\
9 \\
2 \\
1 \\
115\end{array}$ & $\begin{array}{r}1.7 \\
87.9 \\
(2.9) \\
(0.0) \\
(92.1) \\
(5.0) \\
7.9 \\
1.7 \\
0.9 \\
100.0\end{array}$ & $\begin{array}{r}2 \\
97 \\
12 \\
0 \\
78 \\
7 \\
13 \\
2 \\
1 \\
115\end{array}$ & $\begin{array}{c}1.7 \\
84.4 \\
(12.4) \\
(0.0) \\
(80.4) \\
(7.2) \\
11.3 \\
1.7 \\
0.9 \\
100.0\end{array}$ & $\begin{array}{r}2 \\
69 \\
2 \\
0 \\
62 \\
5 \\
9 \\
2 \\
1 \\
83\end{array}$ & $\begin{array}{r}2.4 \\
83.2 \\
(2.9) \\
(0.0) \\
(89.9) \\
(7.2) \\
10.8 \\
2.4 \\
1.2 \\
100.0\end{array}$ \\
\hline
\end{tabular}

*Thirty-two employees did not qualify for any pure exposure group. 
Table 4 Observed deaths and PMR's $\dagger$ during 1950-76 by race for two groups of male chemical workers employed a year or more

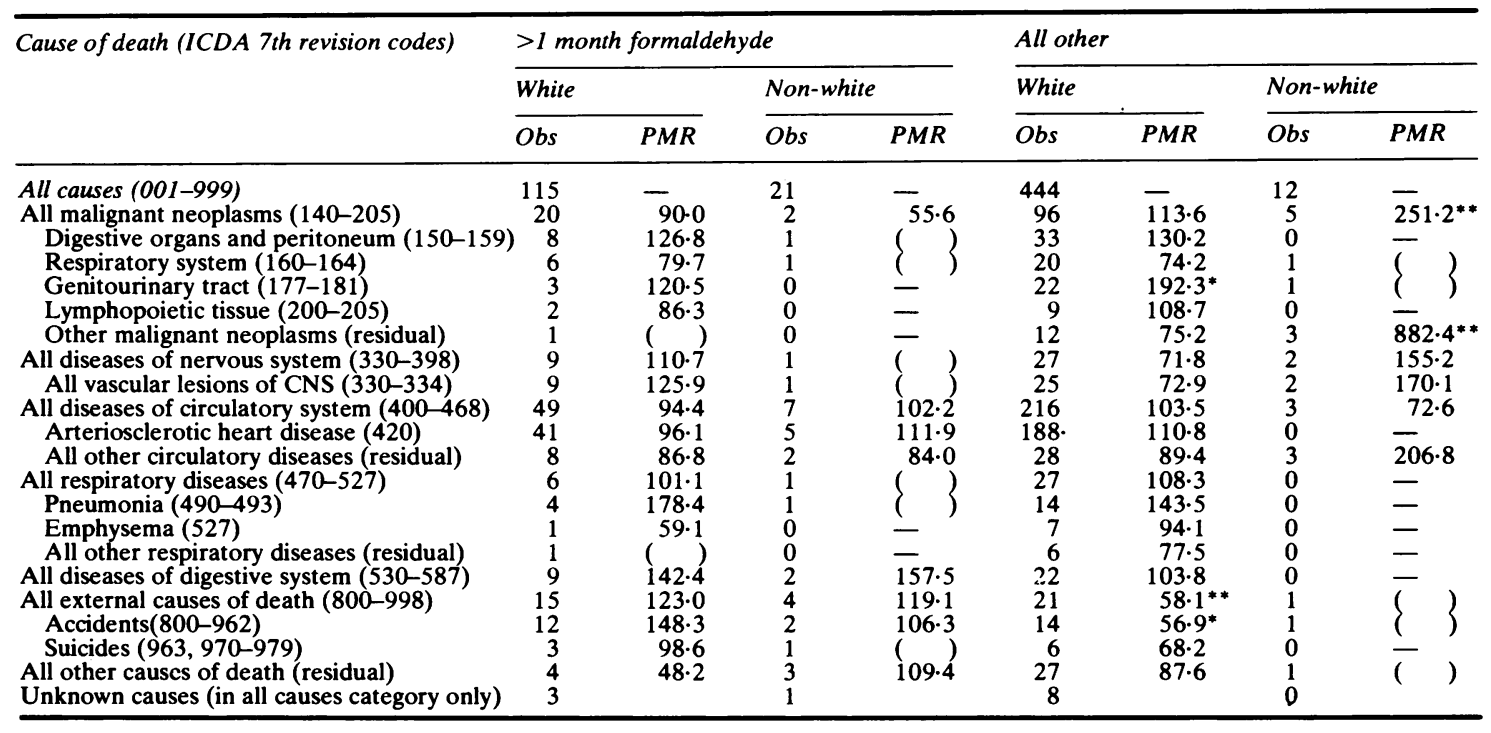

$* \mathrm{p}<0.05$.

$* * \mathrm{p}<0.01$.

$\dagger$ Expected numbers of deaths based on US white and non-white men.

( ) PMRs not shown when based on one observed death.

lar distributions of deaths by plant area. This probably reflects the generally stable nature of the Springfield plant workforce that was noted in an earlier report (Marsh GM, Final report on the Monsanto Company Indian Orchard plant mortality study. Unpublished, University of Pittsburgh, Department of Biostatistics Technical Report, December 1979). Table 3 shows that regardless of the classification scheme used, over $83 \%$ of the decedents were categorised into the Resinox area and, of these deaths, over $80 \%$ were classified into the subarea of moulding powder. None of the schemes categorised any deaths into the Resinox subarea of resin compounding. Unfortunately, the very small numbers of deaths does not permit mortality patterns to be reliably examined for individual plant areas other than Resinox. It was of interest, however, to compare the mortality experience of workers employed in plant areas where formaldehyde is present in a liquid form with potentially higher airborne exposures, with the mortality experience of workers exposed to formaldehyde subsequent to its reaction with other chemicals. Plant area classification scheme 2 (longest duration) was chosen for this comparison, primarily because of the better representation of deaths in plant areas other than Resinox. PMRs for selected causes of death are presented for the two groups of workers defined by the nature of their exposure to formaldehyde.

To investigate the possibility of a dose-response relationship between cancer mortality and exposure to formaldehyde, PMRs were calculated for the formaldehyde-exposed group relative to duration of employment and the interval from the onset of employment until death (latency period). Both duration and latency were measured with respect to only those jobs held in plant areas associated with exposure to formaldehyde. This analysis was done assuming that if deaths from cancer were caused by something in the work environment, such as formaldehyde, the greatest excesses would be expected to appear among those with the greatest exposure and after some time had elapsed.

\section{Results}

\section{GENERAL MORTALITY}

Observed deaths and PMRs by race for selected causes of death for the formaldehyde-exposed workers and all others are shown in table 4. This table shows that for many of the major causes of death the 1950-76 proportional mortality experience of the formaldehyde-exposed workers was similar to that of the unexposed workers. Generally, PMRs were lower among the formaldehyde- 
Table 5 Observed number of deaths and PMRs $\dagger$ by age at death among white male formaldehyde-exposed chemical workers

\begin{tabular}{|c|c|c|c|c|c|c|}
\hline \multirow[t]{3}{*}{ Cause of death (ICDA 7 th revision codes) } & \multicolumn{6}{|c|}{ Age at death } \\
\hline & \multicolumn{2}{|l|}{$<45$} & \multicolumn{2}{|c|}{$45-64$} & \multicolumn{2}{|l|}{$\geqslant 65$} \\
\hline & Obs & $P M R$ & Obs & $P M R$ & Obs & $P M R$ \\
\hline All causes (001-999) & 16 & - & 64 & - & 35 & - \\
\hline All malignant neoplasms (140-205) & 3 & $131 \cdot 0$ & 10 & $\mathbf{7 7 \cdot 0}$ & 7 & $100 \cdot 8$ \\
\hline Digestive organs and peritoneum $(150-159)$ & 2 & $412 \cdot 8^{*}$ & 3 & $81 \cdot 5$ & 3 & $140 \cdot 1$ \\
\hline Respiratory system $(160-164)$ & 0 & & 5 & $106 \cdot 5$ & 1 & \\
\hline Genitourinary tract (177-181) & 0 & - & 2 & $180 \cdot 1$ & 1 & \\
\hline Lymphopoietic tissue $(200-205)$ & 1 & & 0 & - & 1 & \\
\hline Other malignant neoplasms (residual) & 0 & & 0 & - & 1 & \\
\hline All vascular lesions of CNS $(330-334)$ & 0 & - & 4 & $122 \cdot 3$ & 5 & $147 \cdot 4$ \\
\hline All diseases of circulatory system $(400-468)$ & 2 & $43 \cdot 3$ & 35 & $116 \cdot 9$ & 12 & $69 \cdot 3$ \\
\hline All respiratory diseases $(470-527)$ & 0 & & 2 & $69 \cdot 3$ & 4 & $155 \cdot 6$ \\
\hline All externai causes of death $(800-998)$ & 9 & $173.6^{*}$ & 5 & $85 \cdot 1$ & 1 & ( \\
\hline All other causes (residual) & 2 & $68 \cdot 3$ & 6 & $66 \cdot 4$ & 5 & 137.8 \\
\hline Unknown causes (in all causes category only) & 0 & & 2 & & 1 & \\
\hline
\end{tabular}

See footnote to table 4 .

exposed workers for overall cancer mortality and for non-malignant circulatory and respiratory diseases, whereas PMRs were generally higher among this group for non-malignant diseases of the nervous and digestive systems and for external causes of death. Curiously, both exposure groups show similarly raised PMRs for cancer of the digestive system, whereas the excess genitourinary cancers observed in earlier studies of this plant appear to be concentrated in the non-formaldehyde-exposed group.

For the malignant and non-malignant diseases examined, no statistically significant excesses or deficits in deaths were observed among white or non-white wage earners who worked for a month or more in formaldehyde-related plant areas. For white men an overall $20.3 \%$ deficit in deaths from respiratory cancer was observed. Only one such death was found among the non-whites. All seven cancers of the respiratory system observed for the formaldehyde-exposed group were coded to cancer of the bronchus, trachea, or lungs. As of 31 December 1976, there were no deaths from sinonasal cancer among the formaldehyde-exposed or unexposed workers. ${ }^{*}$

Several statistically significant excesses in deaths were observed among the white and non-white non-formaldehyde-exposed workers; however, further interpretation of these findings is beyond the scope of this study. Because of the small number of deaths among the non-whites in this study all subsequent analyses were confined to white men.

Tables 5 and 6 show observed deaths and PMRs for selected causes by age at death and time period, respectively, for the 115 white male formaldehyde-

*In addition, a careful review of all $\mathbf{5 8 0}$ available death certificates showed no mention whatsoever of sinonasal cancer as a contributory cause of death. exposed decedents. The primary interest here is the trends or patterns in PMRs rather than their absolute values. No unusual patterns or trends in proportional mortality by age are discernable in table 5 , but, significantly $(\mathrm{p}<0.05)$ raised PMRs were observed in the youngest age group for cancer of the digestive system ( 2 deaths, PMR $=412 \cdot 8$ ) and for external causes of death ( 9 deaths, PMR $=173 \cdot 6)$.

Table 6 shows PMRs for cancer of the digestive system increasing with time, becoming statistically significant $(\mathrm{p}<0.05)$ during 1970-6 (6 deaths, PMR = 223.9). A rather pronounced downward trend in PMRs was observed for cancer of the respiratory system; however, the small numbers of deaths do not permit a reliable interpretation of this trend to be made. Table 6 shows a significantly $(p<$ 0.05 ) raised PMR in the earliest period examined for "all vascular lesions of the central nervous system" ( 3 deaths, PMR = 284.6), although this excess does not appear to be associated with any type of trend over time.

In calculating PMRs for tables 4, 5, and 6 the expected numbers of deaths were derived from the mortality experience of the entire white or nonwhite male population of the United States. The population in the Springfield, Massachusetts, area has a mortality experience that differs somewhat from that of the entire United States, and some of the excesses and deficits in deaths shown in tables 4 , 5 , and 6 are due to this difference. Table 7 shows how PMRs differ if based on United States proportional mortalities and proportional mortalities computed for Hampden County. For most causes of death examined, geographical variability in proportional mortality between the United States and Hampden County appears to be slight. Notable differences in proportional mortality patterns are evi- 
Table 6 Observed number of deaths and PMRs $\dagger$ by time period among white male formaldehyde-exposed chemical workers

\begin{tabular}{|c|c|c|c|c|c|c|}
\hline \multirow[t]{2}{*}{ Cause of death (ICDA 7th revision codes) } & \multicolumn{2}{|c|}{ 1950-9 } & \multicolumn{2}{|c|}{$1960-9$} & \multicolumn{2}{|c|}{$1970-6$} \\
\hline & Obs & $P M R$ & Obs & $P M R$ & Obs & $P M R$ \\
\hline $\begin{array}{l}\text { All causes (001-999) } \\
\text { All malignant neoplasms }(140-205) \\
\text { Digestive organs and peritoneum (150-159) } \\
\text { Respiratory system }(160-164) \\
\text { Genitourinary tract }(177-181) \\
\text { Lymphopoietic tissue }(200-205) \\
\text { Other malignant neoplasms (residual) } \\
\text { All vascular lesions of CNS (330-334) } \\
\text { All diseases of circulatory system (400-468) } \\
\text { All respiratory diseases (470-527) } \\
\text { All external causes of death (800-998) } \\
\text { All other causes (residual) } \\
\text { Unknown causes (in all causes category only) }\end{array}$ & $\begin{array}{r}18 \\
3 \\
0 \\
2 \\
1 \\
0 \\
0 \\
3 \\
5 \\
1 \\
4 \\
2 \\
0\end{array}$ & $\begin{array}{l}\overline{97 \cdot 0} \\
\overline{237 \cdot 3} \\
(\quad) \\
\overline{-} \\
284 \cdot 6^{*} \\
62 \cdot 9 \\
\left(\begin{array}{r}166 \cdot 6 \\
68 \cdot 9\end{array}\right.\end{array}$ & $\begin{array}{r}47 \\
6 \\
2 \\
2 \\
1 \\
1 \\
0 \\
2 \\
22 \\
3 \\
7 \\
5 \\
2\end{array}$ & 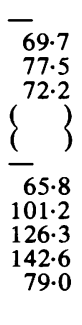 & $\begin{array}{r}50 \\
11 \\
6 \\
2 \\
1 \\
1 \\
1 \\
4 \\
22 \\
2 \\
4 \\
6 \\
1\end{array}$ & $\begin{array}{c}\overline{104.4} \\
223 \cdot 9^{*} \\
51 \cdot 1 \\
\{ \\
\\
\\
130.3 \\
99.1 \\
67.9 \\
81.9 \\
94.2\end{array}$ \\
\hline
\end{tabular}

See footnote to table 4 .

Table 7 Observed numbers of deaths during 1960-76* among white male formaldehyde-exposed chemical workers, showing PMRs based on both US and Hampden County white men

\begin{tabular}{|c|c|c|c|}
\hline \multirow[t]{2}{*}{ Cause of death (ICDA 7th revision codes) } & \multicolumn{3}{|l|}{$P M R$} \\
\hline & Obs & US & Hampden County \\
\hline $\begin{array}{l}\text { All causes (001-999) } \\
\text { All malignant neoplasms }(140-205) \\
\text { Digestive organs and peritoneum (150-159) } \\
\text { Respiratory system }(160-164) \\
\text { Genitourinary tract }(177-181) \\
\text { Lymphopoietic cancer }(200-205) \\
\text { All other cancer (residual) } \\
\text { All vascular lesions of CNS }(330-334) \\
\text { Arteriosclerotic heart disease (420) } \\
\text { All respiratory diseases (470-527) } \\
\text { All external causes of death (800-998) } \\
\text { All other causes (residual) } \\
\text { Unknown causes (in all causes category only) }\end{array}$ & $\begin{array}{r}97 \\
17 \\
8 \\
4 \\
2 \\
2 \\
1 \\
6 \\
36 \\
5 \\
11 \\
19 \\
3\end{array}$ & 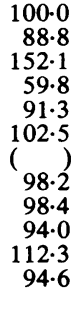 & 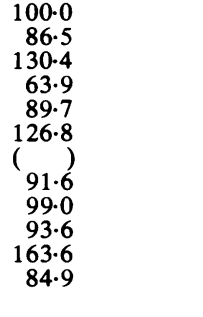 \\
\hline
\end{tabular}

*Hampden County proportional mortalities for non-malignant causes of death were not available for $1950-9$.

( ) PMRs not shown when based on one observed death.

dent, however, for cancer of the digestive system, lymphopoietic cancer, and for external causes of death. Although PMRs based on local mortality patterns may be more valid than those based on the entire United States, they were not used exclusively throughout this report because of the unavailability of a PMR base (all-cause mortality) for a significant portion of the study period. In lieu of this deficiency consideration should be given to the noted geographical variability when interpreting proportional mortality patterns based on the entire United States.

To evaluate the possibility that the overall relative deficit of cancer among white male formaldehyde-exposed workers simply reflects an excess in mortality from other major causes, PCMRs were computed for selected cancer sites.

Table 8 shows for selected cancer sites the comparison of PMRs and PCMRs based on the United States white male mortality experience. With this more conservative approach, proportional cancer mortality during $1950-76$ is somewhat increased; however, the overall excesses and deficits in deaths from cancer shown in table 4 remain statistically non-significant $(p>0.05)$.

\section{MORTALITY IN RELATION TO FORMALDEHYDE EXPOSURE}

Table 9 shows observed deaths and PMRs for selected causes for the two groups of workers defined by the nature of their exposure to formaldehyde. No statistically significant excesses or deficits in deaths were observed in either exposure group for the causes of death examined. Both groups shown similar deficits in total cancer deaths; but digestive system cancer mortality is more raised among the workers whose longest exposure was to formaldehyde in the solid form.

Table 10 shows that, overall, the formaldehyde exposures among the study group were relatively brief, since onc-half were employed less than 2.5 
Table 8 Comparison of proportional cancer mortality ratios with proportional mortality ratios during 1950-76 for white male formaldehyde-exposed chemical workers for selected cancer sites

\begin{tabular}{lrr}
\hline Cause of death (ICDA 7th revision codes) & Obs & $P C M R \dagger$ \\
\hline All malignant neoplasms (140-205) & PMR \\
Digestive organs and peritoneum (150-159) & 20 & $100 \cdot 0$ \\
Respiratory system (160-164) & 8 & $141 \cdot 9$ \\
Genitourinary tract (177-181) & $60 \cdot 0$ \\
Lymphopoietic cancer (200-205) & 3 & $88 \cdot 4$ \\
All other cancer (residual) & $26 \cdot 8$ & $130 \cdot 4$ \\
\hline
\end{tabular}

$\dagger$ Expected numbers of deaths based on US white male proportional cancer mortality.

F Expected numbers of deaths based on US white male proportional mortality (all causes).

( ) PMRs and PCMRs not shown when based on one observed death.

Table 9 Observed numbers of deaths and PMRs $\ddagger$ during 1950-76 among white male formaldehyde-exposed chemical workers by nature of exposure to formaldehyde

\begin{tabular}{|c|c|c|c|c|}
\hline \multirow[t]{3}{*}{ Cause of death (ICDA 7th revision codes) } & \multicolumn{4}{|c|}{ Nature of formaldehyde-exposure of longest duration } \\
\hline & \multicolumn{2}{|c|}{ Liquid form* } & \multicolumn{2}{|c|}{ Solid form $\dagger$} \\
\hline & Obs & $P M R \ddagger$ & Obs & $P M R \ddagger$ \\
\hline All causes (001-999) & 36 & $100 \cdot 0$ & 79 & $100 \cdot 0$ \\
\hline All malignant neoplasms $(140-205)$ & 6 & $84 \cdot 1$ & 14 & $92 \cdot 8$ \\
\hline Digestive organs and peritoneum $(150-159)$ & 2 & $104 \cdot 6$ & 6 & $136 \cdot 5$ \\
\hline Respiratory system $(160-164)$ & 1 & & 5 & $100 \cdot 2$ \\
\hline Genitourinary tract $(177-181)$ & 1 & & 2 & 113.6 \\
\hline Lymphopoietic cancer $(200-205)$ & 1 & & 1 & $(\quad)$ \\
\hline Other malignant neoplasms (residual) & 1 & & 0 & -1 \\
\hline Vascular lesions of CNS $(330-334)$ & 2 & 98.9 & 7 & $136 \cdot 2$ \\
\hline All diseases of circulatory system $(400-468)$ & 13 & $82 \cdot 0$ & 36 & 99.9 \\
\hline All respiratory diseases $(470-527)$ & 2 & $109 \cdot 2$ & 4 & $97 \cdot 5$ \\
\hline All external causes $(800-998)$ & 6 & $141 \cdot 5$ & 9 & $113 \cdot 2$ \\
\hline All other causes (residual) & 7 & 142.6 & 6 & $56 \cdot 1$ \\
\hline Unknown causes (in all causes category only) & 0 & & 3 & \\
\hline
\end{tabular}

* Comprised of plant areas: cast phenolics, resins, other resinox, resimines, formalin.

$\dagger$ Comprised of plant areas: moulding powder, service department.

¥ Expected numbers of deaths based on US white men.

( ) PMRs not shown when based on one observed death.

years in one or more of the five formaldehyderelated plant areas. Moreover, these jobs on the average comprised only about one-quarter of their overall employment history at the plant. There does appear to have been a sufficient latent period for the development of chronic diseases, however, since table 10 shows that among the 115 decedents an average of 18.8 years elapsed between the initial exposure to formaldehyde and death.

Tables 11,12 , and 13 show observed numbers of deaths and PMRs for categories of cancer that contained a sufficient number of deaths to permit cross-tabulation by the latency period and duration of employment associated with formaldehyderelated jobs. There is no suggestion in the marginal totals of table 11 that a dose-response relationship exists between exposure to formaldehyde and overall cancer mortality among the chemical workers studied. Moderately raised PMRs were observed within the internal cells of table 11 ; however, their pattern relative to latency and duration suggests that these excesses may be due to factors other than formaldehyde exposure.

The marginal totals of table 12 show an unusual pattern of PMRs for cancer of the digestive system. While over twice as large after 20 years from first employment (compared with under 20 years), PMRs are only about one-half as large among workers with over five years of exposure (compared with under five years). If a dose-response relationship existed here the PMR would be expected to be at least as large if not considerably larger for those workers with the greatest duration of exposure. The statistically significant $(p<0.01)$ cluster of deaths from cancer of the digestive system (5 observed, PMR $=320 \cdot 1)$ within table 12 may be important or may simply be a chance occurrence arising from the multiple comparisons that were made. ${ }^{*}$ It should also be recognised that at least part of the excesses shown in table 12 are due to the generally higher local proportional mortality for cancer of the digestive system shown in table 6 .

Table 13 shows that cancer of the respiratory system mortality was substantially higher among work- 
Table 10 Characteristics of employment among 115 deaths of white male chemical workers (1950-76)

\begin{tabular}{llllll}
\hline & $\begin{array}{l}\text { Duration of employment } \\
\text { (years) }\end{array}$ & $\begin{array}{l}\text { Latency period } \\
\text { (years) }\end{array}$ & \\
\cline { 2 - 3 } \cline { 5 - 6 } & Formaldehyde & Overall & Formaldehyde & Overall \\
\hline Mean & 4.5 & 16.9 & 18.8 & 22.5 \\
Median & 2.5 & 16.3 & 19.6 & 20.7 \\
Minimum & 0.1 & 1.2 & 2.4 & 2.4 \\
Maximum & 18.8 & 37.0 & 37.9 & 53.3 \\
\hline
\end{tabular}

Table 11 Observed deaths and PMRs $\dagger$ for all malignant neoplasms among white male formaldehyde-exposed chemical workers during 1950-76 by latency period and duration of employment (measured from first formaldehyde job)

\begin{tabular}{llccc}
\hline Latency (years) & \multicolumn{4}{c}{ Duration (years) } \\
\cline { 3 - 5 } & & $<5$ & $\geqslant 5$ & Total \\
\hline \multirow{2}{*}{$<20$} & Obs & 4 & 5 & 9 \\
& PMR & 47.0 & 143.8 & 75.0 \\
220 & Obs & 9 & 2 & 11 \\
& PMR & 155.9 & 44.8 & 107.5 \\
Total & Obs & 13 & 7 & 20 \\
\hline
\end{tabular}

$\dagger$ Expected number of deaths based on US white men.

Table 12 Observed deaths and PMRs $\dagger$ for digestive system cancer among white male formaldehyde-exposed chemical workers during 1950-76 by latency period and duration of employment (measured from first formaldehyde exposure)

\begin{tabular}{llccc}
\hline Latency (years) & \multicolumn{4}{c}{ Duration (years) } \\
\cline { 2 - 5 } & & $<5$ & $\geqslant 5$ & Total \\
\hline \multirow{2}{*}{$<20$} & Obs & 1 & 2 & 3 \\
& PMR & $41 \cdot 5$ & $183 \cdot 3$ & $85 \cdot 7$ \\
20 & Obs & 5 & 0 & 5 \\
& PMR & $320 \cdot 1^{* *}$ & - & $178 \cdot 1$ \\
Total & Obs & 6 & 2 & 8 \\
\hline
\end{tabular}

${ }^{* *} \mathrm{p}<0.01$.

$\dagger$ Expected number of deaths based on US white men.

ers with five or more years of formaldehyde-related employment compared with those employed for under five years. By contrast with this finding, however, table 13 shows an approximate $20 \%$ deficit in respiratory cancer mortality both before and after 20 years from onset of the first exposure to formaldehyde. Although the very small numbers of deaths

${ }^{*}$ Four of the five cancers of the digestive system were categorised Resinox/moulding powder according to scheme 2 (longest duration) and one was classified into Resinox resins.
Table 13 Observed deaths and PMRs† for cancer of the respiratory system among white male formaldehydeexposed chemical workers during 1950-76 by latency period and duration of employment (measured from first exposure to formaldehyde)

\begin{tabular}{llccc}
\hline Latency (years) & & \multicolumn{3}{c}{ Duration (years) } \\
\cline { 3 - 5 } & & $<5$ & $\geqslant 5$ & Total \\
\hline \multirow{2}{*}{$<20$} & Obs & 1 & 2 & 3 \\
& PMR & $35 \cdot 7$ & $183 \cdot 8$ & $77 \cdot 1$ \\
\multirow{2}{*}{20} & Obs & 1 & 2 & 3 \\
& PMR & $47 \cdot 5$ & $130 \cdot 4$ & $82 \cdot 5$ \\
Total & Obs & 2 & 4 & 6 \\
\hline
\end{tabular}

† Expected number of deaths based on US white men.

here do not permit a definitive interpretation to be made, these two findings are inconsistent, and do not support the existence of a dose-response relationship between exposure to formaldehyde and respiratory cancer.

\section{Discussion}

The present study has certain limitations that make it difficult to draw definite conclusions. Firstly, risk estimates obtained from PMR analyses only approximate the results from studies of cause-specific disease rates. Although PMRs are often similar to risk estimates when the population at risk is available, ${ }^{11}$ they may be inflated for certain causes when the overall mortality of the study group is lower than that of the comparison population, as is usually the case with working populations..$^{12}$

Secondly, a special problem for studies of chemical plant workers is uncertainty as to just what exposures and combination of exposures took place. Most of the workers studied in this report were probably not exposed to formaldehyde alone but rather to a great number of chemicals that have been used in the manufacture of the major products made at the Springfield plant. A partial list of other chemicals used or produced during the history of operations includes phenol, cellulose acetate, polyvinyl butyral, amino plastics, polystyrene, and various vinyl chloride products, including vinyl chloride polymers. Although established chronic disease risks have not been associated with most of these chemicals, exposure to vinyl chloride and its polymers has been linked with raised risks for angiosarcomas of the liver, cancers of the digestive and respiratory systems, cancer of the brain, and lymphomas. ${ }^{13-15}$ Exposures to vinyl chloride most probably did not occur in the plant areas associated with formaldehyde; possibly, some men were exposed to 
this chemical at some time during their work history at the plant. It is uncertain now whether these possible exposures to vinyl chloride in any way affected the proportional mortality patterns among the workers studied in this report.

Thirdly, examining the proportional mortality experience of the formaldehyde-exposed workers relative to race, calendar time, age, duration of employment, and latency period generally resulted in very small numbers of deaths within most subcategories. This was particularly true for malignant neoplasms, which were studied in great detail. The small numbers of deaths in these subcategories often made trends or patterns in mortality difficult to discern. This was a particular hindrance in this study for without knowledge of actual historical formaldehyde-exposure levels, these trends and patterns provided the only means of systematically evaluating mortality in relation to occupational factors.

Small sample size was also a problem in examining proportional mortality relative to the nature of the exposure to formaldehyde. Over $68 \%$ of the white male study group spent the largest portion of their formaldehyde-related employment in plant areas where formaldehyde existed in combination with other chemicals as a solid or powdered substance. Except for rare instances, airborne exposures to formaldehyde vapour in these areas were probably very low. This means that only 36 members of this study group had worked for most of their employment in areas where significant exposures to formaldehyde vapour could have occurred routinely. Clearly, further studies of much larger groups of such workers are needed before an accurate and reliable assessment may be made of the possible mortality risks associated with exposures to formaldehyde.

Despite the aforementioned limitations, the results of this study did not show any trends or patterns in proportional mortality that could be directly linked to occupational exposures to formaldehyde at the Springfield plant.

This study was supported by a contract between the Monsanto Company and the University of Pittsburgh.

I gratefully acknowledge the clerical and technical help provided by several employees of the Monsanto Company Springfield plant. Ms Michele LaValley, Mrs Vanessa Gleason, and Mr Donald Fisherowski of the department of biostatistics helped in the data processing operations and Miss Mary Preininger provided the computer programming support.

\section{Addendum}

Subsequent to the closing date of this study ( 31 December 1976) one death from nasopharyngeal cancer occurred in 1979 in a 58-year-old member of the Springfield cohort who had worked between the years 1947 and 1954 in plant areas associated with exposure to formaldehyde. About $80 \%$ of this time was spent in the cast phenolics area, where formaldehyde was present in the liquid form. This nasopharyngeal cancer is, however, aetiologically distinct from nasal cancer, such as was found in the CIIT rat studies.

\section{References}

' Blackwell M, Kang H, Thomas A, Infante P. Formaldehyde: evidence for carcinogenicity. Am Ind Hyg Assoc J $1981 ; 42 ; A: 34-46$.

${ }^{2}$ United States International Trade Commission. Synthetic organic chemicals-United States production and sales, 1978. (Publication 1001.) Washington, DC: USITC 1979:311.

${ }^{3}$ National Institute for Occupational Safety and Health. Criteria for a recommended standard: occupational exposure to formaldehyde. Washington: United States Government Printing Office, 1976. (HEW(NIOSH) Publication No 77-126.

${ }_{4}^{4}$ Proctor NH, Hughes JP. Chemical hazards of the workplace. Philadelphia: JB Lippincott Co, 1978.

s Chemical Industry Institute of Toxicology. Progress report on CIIT formaldehyde status (1/16/80). North Carolina: CIIT, 1980.

- Swenberg JA, Kerns WD, Mitchell RI, Gralla EJ, Pavkov KL. Induction of squamous cell carcinomas of the rat nasal cavity by inhalation exposure to formaldehyde vapor. Cancer Research 1980;40:3398-401.

7 Auerbach C, Moutschen-Dahmen M, Moutschen J. Genetic and cytogenetical effects of formaldehyde and related compounds. Mutat Res 1977;39:317-61.

${ }^{8}$ National Center for Health Statistics. Seventh revision international classification of disease adapted for use in the United States. Vol 1, tabular list; Vol 2, alphabetical index. Washington: United States Government Printing Office, 1957.

${ }^{9}$ Marsh GM, Preininger M. OCMAP: a user-oriented occupational cohort mortality analysis program. American Statistician 1980;34:245-6.

${ }^{10}$ Miettinen OS. Estimability and estimation in case-referent studies. Am J Epidemiol 1976;103:226-35.

${ }^{11}$ Kupper LL, McMichael AJ, Symons MJ, Most BM. On the utility of proportional mortality analysis. $J$ Chronic Dis 1978;31:15-22.

12 McMichael AJ. Standardized mortality ratios and the "healthy worker effect": scratching beneath the surface. JOM 1976;18: $165-8$.

13 Tabershaw I, Gaffey W. Mortality study of workers in the manufacture of vinyl chloride and its polymers. JOM 1974;16:509-18.

14 Waxweiler R, Stringer W, Wagoner J, et al. Neoplastic risk among workers exposed to vinyl chloride. Ann NY Acad Sci 1976;271:40-8.

15 Monson R, Peters J. Proportional mortality among vinyl chloride workers. Lancet 1974;ii:397-8. 